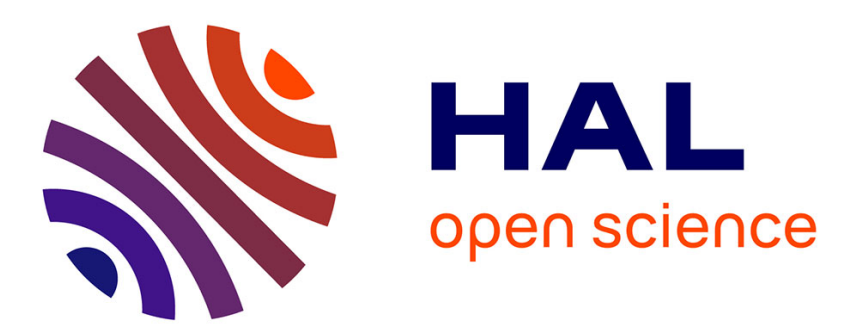

\title{
Nonsmooth fracture dynamics of functionnaly graded materials
}

\author{
Frédéric Pérales, Yann Monerie, André Chrysochoos
}

\section{To cite this version:}

Frédéric Pérales, Yann Monerie, André Chrysochoos. Nonsmooth fracture dynamics of functionnaly graded materials. Journal de Physique IV Proceedings, 2006, EURODYMAT 2006 - 8th International Conference on Mechanical and Physical Behaviour of Materials under Dynamic Loading, 134, pp.367371. 10.1051/jp4:2006134056 . hal-00572476

\section{HAL Id: hal-00572476 https://hal.science/hal-00572476}

Submitted on 17 Feb 2021

HAL is a multi-disciplinary open access archive for the deposit and dissemination of scientific research documents, whether they are published or not. The documents may come from teaching and research institutions in France or abroad, or from public or private research centers.
L'archive ouverte pluridisciplinaire HAL, est destinée au dépôt et à la diffusion de documents scientifiques de niveau recherche, publiés ou non, émanant des établissements d'enseignement et de recherche français ou étrangers, des laboratoires publics ou privés. 


\title{
Nonsmooth fracture dynamics of functionally graded materials
}

\author{
F. Perales ${ }^{1}$, Y. Monerie ${ }^{1}$ and A. Chrysochoos ${ }^{2}$ \\ 1 Institut de Radioprotection et de Sûreté Nucléaire, DPAM, SEMCA, \\ LEC, BP. 3, 13115 St-Paul-Lez-Durance Cedex, France \\ ${ }^{2}$ Laboratoire de Mécanique et Génie Civil, CC048, Place E. Bataillon, \\ 34095 Montpellier Cedex 5, France
}

\begin{abstract}
This paper presents a numerical framework for the simulation of dynamic fracture of heterogeneous material. It consists in a multibody approach based both on the concept of Frictional Cohesive Zone Model and on NonSmooth Contact Dynamics. The heterogeneities of the material are taken into account using a multiscale method. The microscopic scale corresponds to the scale of heterogeneities. The macroscopic scale corresponds to the structure where gradients of properties will be invoked. The ability of the framework is illustrated by the fracture of hydrided Zircaloy-4, constituting nuclear cladding tube, under transient loading.
\end{abstract}

\section{INTRODUCTION}

The core of a Pressurized Water Reactor (PWR) contains a stack of fuel pellets surrounded by a Zircaloy cladding tube. During nuclear reactor operation, the microstructure of these tubes evolves because of the migration/precipitation of hydrogen. The microstructure appears as a two phase material constituted of zirconium hydrides platelets embedded in a Zircaloy metal matrix. The hydride-induced embrittlement can lead to the failure of the fuel rods under accident conditions.

In the frame of the French "Institut de Radioprotection et de Sûreté Nucléaire" (IRSN) research program on nuclear fuel safety under accident conditions, a new numerical framework dedicated to the study of the dynamic fracture of heterogeneous and functionally graded materials has then been developed. The framework consists in a micromechanical approach, based on both the concept of Frictional Cohesive Zone Model (FCZM) and a multibody method in the context of the NonSmooth Contact Dynamics (NSCD).

The FCZM couples standard cohesive zone model, describing the vectorial traction - separation relationship in the fracture process zone, with nonsmooth surface behaviors such as frictional contact. Since dynamic problems involving unilateral contraints are not regular (velocity can become discontinuous), the NSCD approach is used in order to solve the equations of the frictional contact without any regularization nor penalization. These modelings are developed in a total lagrangian finite deformation formulation, implicit dynamics and periodic homogenization.

The associated software is composed of three libraries, each dealing with a part of the mechanical problem. The ability of the numerical framework and of the associated platform are illustrated by two examples. The first one quantifies the weakening effect of brittle inclusions in an elastoplastic matrix. The second one deals with the dynamic fracture of a functionally graded material at the scale of the structure.

\section{MULTIBODY APPROACH AND FRICTIONAL COHESIVE ZONE MODEL}

To analyse the effects of the microstructure heterogeneity on the material behavior, a micromechanical modeling based on a multibody concept and FCZM is proposed. The multibody system consists in 
independant meshes connected one to each other with FCZM-type interface relationship. The bulk volumic behaviors inside the meshes as well as the surface properties of the FCZM vary with the position in space. This variation is related to the phases of a composite material, for example at the microscale, or to continuous properties such as graded properties, at the macroscale.

The FCZM concept represents the physics of the fracture process at the crack tip, from crack initiation to post-fracture unilateral contact and friction. The present model [7] is inspired by the adhesive-friction law of Raous et al. [9] and by the surface damage law of Michel et al. [4]. A cohesive stress, denoted by $\mathbf{R}^{\mathrm{coh}}$, is added on the Signorini-Coulomb complementary problem (1)-(2) and related to the displacement jump [u] accross the crack lips (3) :

$$
\begin{aligned}
& 0 \diamond\left(\mathrm{R}_{\mathrm{N}}+\mathrm{R}_{\mathrm{N}}^{c o h}\right) \diamond \mathrm{u}_{\mathrm{N}} \diamond 0, \\
& \left\{\begin{array}{c}
|| \mathrm{R}_{\mathrm{T}}+\mathrm{R}_{\mathrm{T}}^{\text {coh }} \|<\mu\left|\mathrm{R}_{\mathrm{N}}+\mathrm{R}_{\mathrm{N}}^{\text {coh }}\right| \otimes \dot{\mathrm{u}}_{\mathrm{T}}=0 \\
|| \mathrm{R}_{\mathrm{T}}+\mathrm{R}_{\mathrm{T}}^{\text {coh }} \|=\mu\left|\mathrm{R}_{\mathrm{N}}+\mathrm{R}_{\mathrm{N}}^{\text {coh }}\right| \diamond \lambda \diamond 0 \text { such as } \dot{\mathrm{u}}_{\mathrm{T}}=-\lambda\left(\mathrm{R}_{\mathrm{T}}+\mathrm{R}_{\mathrm{T}}^{\text {coh }}\right)
\end{array}\right. \\
& \mathrm{R}^{\mathrm{coh}}=\beta\left(\mathrm{C}_{\mathrm{N}} \mathrm{n} \otimes \mathrm{n}+\mathrm{C}_{\mathrm{T}} \frac{\mathrm{u}_{\mathrm{T}} \otimes \mathrm{u}_{\mathrm{T}}}{\left\|\mathrm{u}_{\mathrm{T}}\right\|^{2}}\right) \cdot[\mathrm{u}] \text { and } \beta=\min \left(g(\|[\mathrm{u}]\|), g\left(\left\|\left[\mathrm{u}_{\max }\right]\right\|\right)\right) \text {. }
\end{aligned}
$$

Subscripts $N$ and $T$ respectively denote the normal and tangential components $\left(\mathbf{R}=R_{N} \mathbf{n}+R_{T}\right.$, $\mathrm{R}^{\text {coh }}=R_{N}^{\text {coh }} \mathbf{n}+\mathbf{R}_{T}$ and $\left.[\mathbf{u}]=u_{N} \mathrm{n}+\mathrm{u}_{T}\right), \mathrm{n}$ is the unit normal vector of the cohesive zone, $C_{N}$ and $C_{T}$ denote respectively the initial normal and tangent stiffness of the perfect interface $(\mathrm{MPa} / \mathrm{m}), \mathbf{u}_{\max }$ is the maximum value reached by $\mathbf{u}$ during the fracture process, $g$ is a decreasing function of $11[\mathbf{u}] 11$ (progresive softening), $\mu$ is the Coulomb friction and $\beta$ is a surface variable $(\beta=1$ : the interface is undamaged, $0<\beta<1$ : the interface is partially damaged and $\beta=0$ : the interface is fully damaged). The damage evolution is governed by :

$$
g(x)=\beta_{0} \text { if } x \leq \delta_{0}, \quad g(x)=0 \text { if } x \geq \delta_{c}, \quad g(x)=\frac{\beta_{0}\left(\delta_{c}-x\right)}{\delta_{c}-2 \delta_{0}+x} \text { if } \delta_{0}<x<\delta_{c},
$$

where $\delta_{0}=\sqrt{\frac{w}{(9-4 \ln 4)}\left(\frac{1}{C_{N}}+\frac{1}{C_{T}}\right)}, \delta_{c}=3 \delta_{0}, 0 \leq \beta_{0} \leq 1$, is an initial surface damage and $w$ is a reference fracture energy $\left(\mathrm{J} / \mathrm{m}^{2}\right)$. In a $2 \mathrm{D}$ case, Fig. 1 shows the normal and the tangential behavior associated to the FCZM (1)-(4).

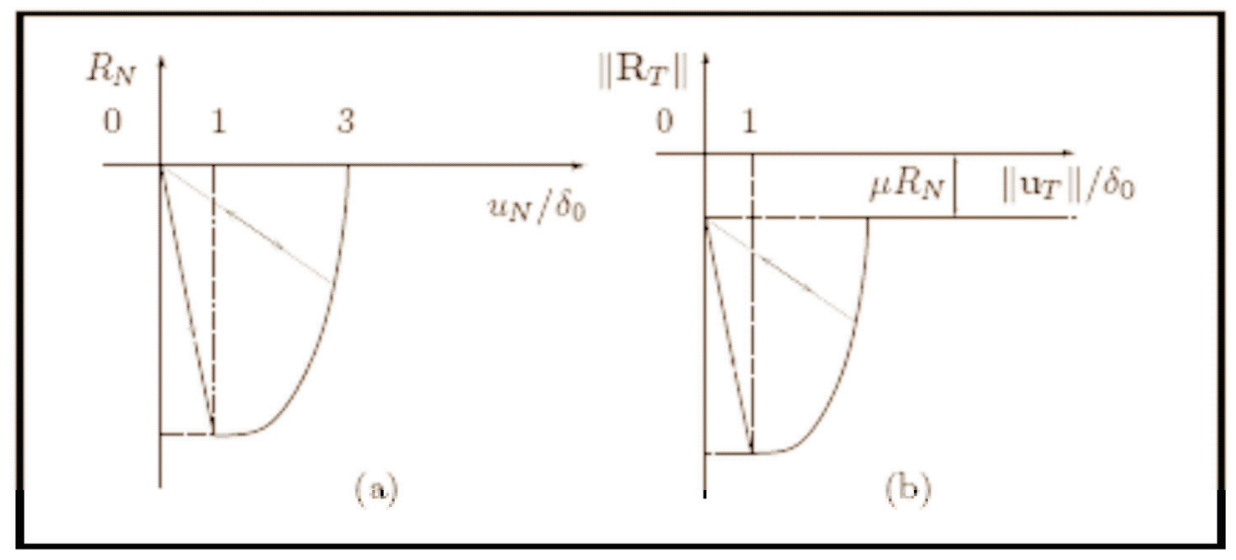

Figure 1. The 2D FCZM : (a) normal behavior $\left(u_{T}=0\right)$ - (b) tangent behavior $\left(R_{N}\right.$ constant, $\left.u_{N}=0\right)$. 


\section{NONSMOOTH CONTACT DYNAMICS AND FCZM}

Denoting $\mathrm{M}$ the mass matrix, $\mathbf{q}, \dot{\mathbf{q}}$ and $\ddot{\mathbf{q}}$ respectively the discrete displacement, the velocity and the acceleration, $\mathrm{F}(\mathbf{q}, \dot{\mathbf{q}}, t)$ the internal and external forces and $\mathbf{r}$ the representative of local reaction forces, the investigated dynamic problem is composed of equations (1)-(4) and the discrete dynamic equation:

$$
M \ddot{\mathbf{q}}=\mathrm{F}(\mathbf{q}, \dot{\mathbf{q}}, t)+\mathbf{r}
$$

The equation (5) is treated without any regularization nor penalization techniques using the frame of the NSCD approach [3] and the functional framework de ned by Moreau [6]. In particular, the derivatives are written in the sense of the distribution and the time integration scheme is implicit.

Using linear mappings between global unknowns (velocity $\dot{\mathbf{q}}$ and impulse $h \mathbf{r}$ ) and their relative contreparts ( $\dot{\mathbf{U}}$ and $h \mathbf{R}$ ), and previous formulation of Monerie and Acary [5], the three dimensional system to solve for each contact $\alpha$ writes [3]:

$$
\dot{\mathbf{U}}^{\alpha}=\dot{\mathbf{U}}_{\mathrm{f}}^{\alpha}+\mathbf{W}^{\alpha \alpha} h\left(\mathbf{R}-\mathbf{R}^{\mathrm{coh}}\right)^{\alpha}, \quad R_{N}^{\alpha}=\operatorname{proj}_{\Re}+\left(R_{N}^{\alpha}-\rho U_{N}^{\alpha}\right), \quad \mathbf{R}_{T}^{\alpha}=\operatorname{proj}_{D}+\left(\mathbf{R}_{T}^{\alpha}-\rho \dot{\mathbf{U}}_{T}^{\alpha}\right)
$$

where $\rho>0$ and $D$ is the section of Coulomb's cone for contact $\alpha, \mathbf{U}_{\mathrm{f}}^{\alpha}$ is the velocity at the contact in the absence of contact $\alpha$ and $h$ is the length of the time step. The system is solved using the generalized Newton method of Alart and Curnier [1].

\section{NUMERICAL SOFTWARE}

The application software, called 'X-per', is written using Object Oriented and Mixed Programming. The conception rests on three libraries having a clear mechanical meaning : 1) a library dedicated to contact problems using NSCD approach (LMGC90, [2]), 2) a Finite Element library (PELICANS, [8]), and 3) a material constitutive models library (MatLib, [10] ).

The software allows to simulate, in finite deformation, the dynamic fracture of heterogeneous materials from the crack initiation to post-fracture behavior.

\section{APPLICATIONS}

\subsection{Influence of brittle phase on the fracture of an elastoplastic material}

This application deals with the numerical simulation of the damage elastoplastic behavior of the Zircaloy-4. At the microscale, the numerical simulations have been made using periodic Representative

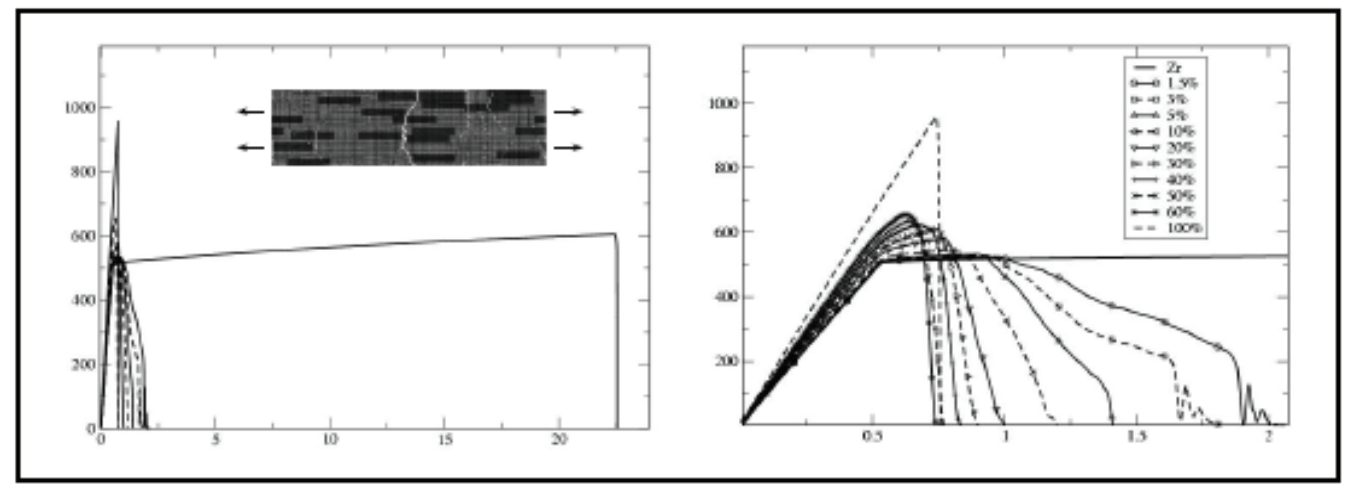

Figure 2. Overall stress $(\mathrm{MPa})$ /strain (\%) curve of the hydrided Zircaloy-4 for various hydrogen contents, with a zoom at small strains (right). 


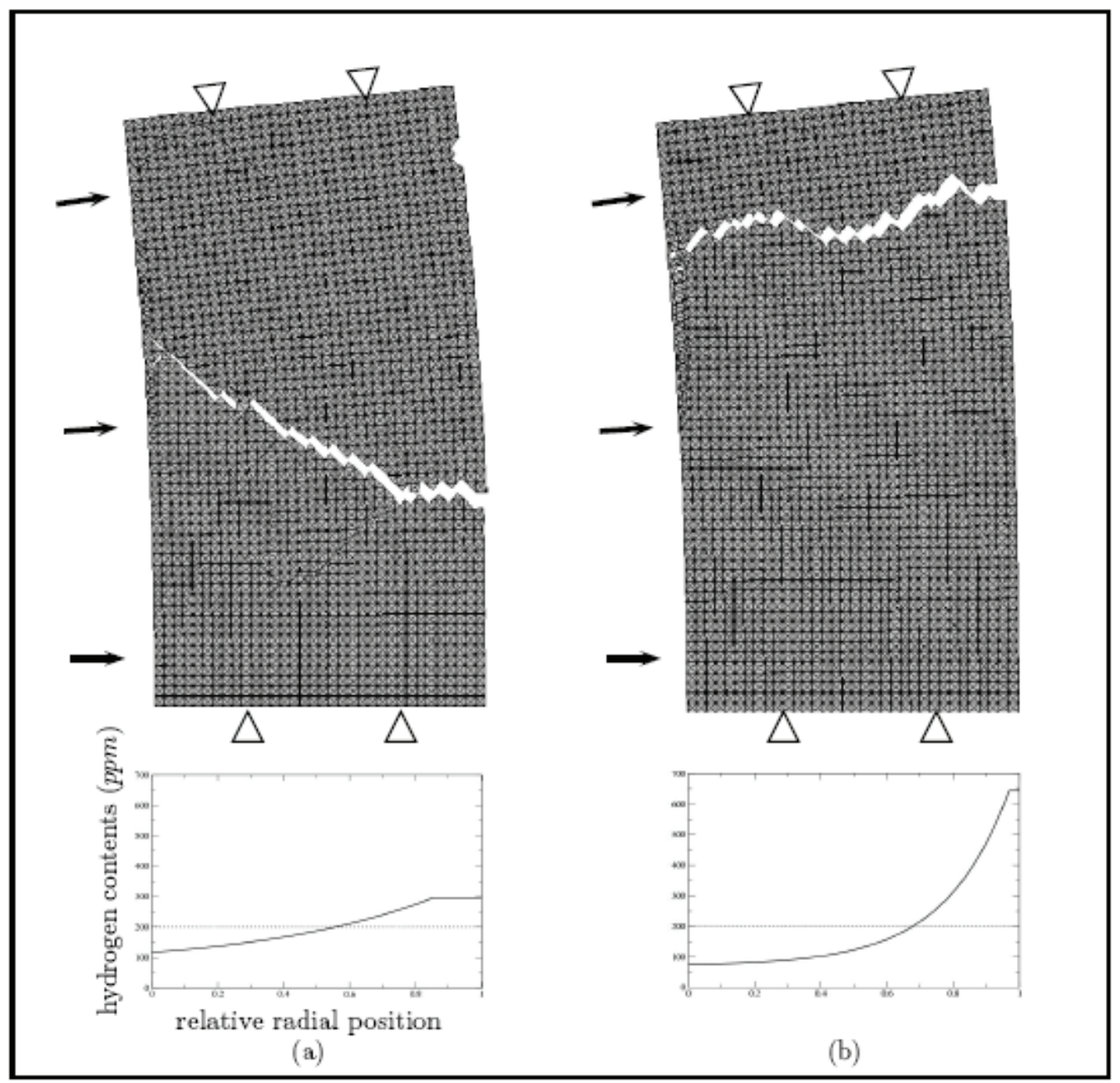

Figure 3. Influence of the profile gradient of hydrogen contents on the dynamic rupture features of a part of cladding tube : (a) low gradient $(p=0.5)$ : crack branching along shear band; (b) high gradient $(p=0.8)$ : quasi-brittle fracture.

Volume Elements for various volume fractions of inclusions. Each microstructure is composed of a metal matrix (Zircaloy-4) and rectangular aligned inclusions randomly distributed (zirconium hydrides). The Zircaloy-4 behavior is assumed to be elastoplastic ( $\mathrm{J} 2$ plasticity, $\mathrm{E}=99 \mathrm{GPa}, \mathrm{v}=0.325, \sigma_{0}=450 \mathrm{MPa}$, $\left.H_{Y}=850 \mathrm{MPa}\right)$ and hydrides to be elastic $(\mathrm{E}=135 \mathrm{GPa}, v=0.32)$. The FCZM coefficients of Zircaloy-4, zirconium hydrides and Zircaloy-hydride interface are respectively: $C_{N}^{Z r}=2 \times 10^{18} \mathrm{~Pa} / \mathrm{m}$ and $w^{Z r}=1 J / m^{2}, C_{N}^{Z r H}=2 C_{N}^{Z r}$ and $w^{Z r H}=0.8 w^{Z r}, C_{N}^{Z r-Z r H}=2 C_{N}^{Z r}$ and $w^{Z r-Z r H}=0.8 w$.

Moreover, we assume a low friction coefficient $\mu=0.05$ and same compliance for the normal and tangential behaviors $C_{N}=C_{T}$. A macroscopic strain gradient rate is prescribed along the direction of the aligned inclusions $\left(\dot{\overline{\mathrm{F}}}_{x x}=10^{6} \mathrm{~s}^{-1}\right)$ and the resulting stress/strain curves are plotted on Fig. 2 for various volume fraction of inclusions.

A key feature of these simulations is that the overall elastoplastic and damageable behaviour of the Zircaloy matrix is conveniently described by the dynamic multibody approach without any viscous regularization, neither in the bulk behaviors (in the meshes), nor in the interfaces (in the FCZM). In 
addition, the Fig. 2 shows the deleterious influence of the hydride on the material ductility: the ultimate tensile elongation decreases rapidly with hydrogen contents.

\subsection{Dynamic fracture of an heterogeneous cladding tube}

This second application deals with the macroscopic fracture of an hydrided Zircaloy-4 cladding tube with a gradient of hydrogen contents. At this scale, the volumic bulk behaviors are derived with the help of some analytical homogeneization techniques in a separate work [11] and surfacic behaviors of the FCZM are given by the results of the previous section. These volumic and surfacic behaviors depend on hydrogen contents and are respectively introduced at the Gauss points and at the contacts node where the FCZM is integrated.

The simulations are performed on a part of a cladding tube in two dimensions and in a plane perpendicular to the axis of the tube. Various mean hydrogen contents $[\overline{\mathrm{H}}]$ and various profile gradients are investigated. The hydrogen gradients are characterized by a parameter $p(p=0$ : no gradient, $p=1$ : limit case of a bimaterial microstructure). A radial velocity $\mathrm{v}_{\mathrm{r}}=20 \mathrm{~ms}^{-1}$ is imposed on the inner side of the tube. Precracks are present in an outer layer, corresponding to some highly brittle zirconia.

Fig. 3 shows the rupture features for $[\overline{\mathrm{H}}]=200 \mathrm{ppm}$ and two gradients $p=0.5$ and $p=0.8$. Crack propagates rapidly from the outer side to the inner side in the high hydrogen concentration area. If this area is small enough $(p=0.5)$, the crack velocity decreases progressively and a crack branching can appear along some shear bands. Otherwise $(p=0.8)$, the precrack is long enough to go through the entire structure leading to a brittle failure of the cladding tube.

Fig. 4 shows the importance of the profile gradient in the fracture toughness. Below $p=0.9$, the higher the gradient, the lower the fracture energy: the gradient acts as a precrack whose length grows with $p$. Above this value, the gradient becomes beneficial for the fracture toughness: the microstructure tends to a bimaterial which can accomodate a part of the shear strain at its interface.

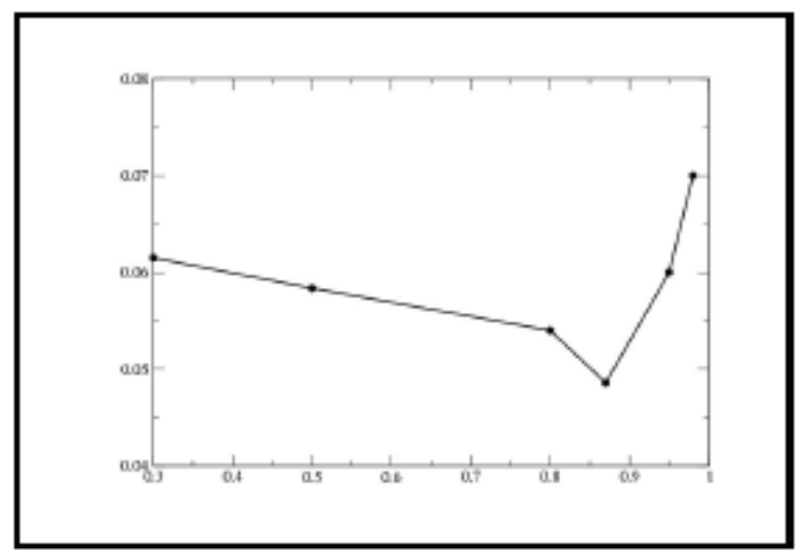

Figure 4. Energy $\left(\mathrm{Jm}^{-2}\right)$ vs profile gradient for $200 \mathrm{ppm}$ of hydrogen.

\section{CONCLUSION}

This paper has presented a numerical framework for the dynamic fracture of heterogeneous materials. The framework consists in a multibody approach based on the concept of Frictional Cohesive Zone Model and NonSmooth Contact Dynamics approach. The associated numerical platform is developed by coupling libraries with Oject Oriented and Mixed Programming. The efficiency of this numerical 
framework was underlined on the multiscale simulation of a functionally graded metal matrix composite from the nuclear industry. In particular, the intensity of heterogeneity profile gradient minimizing the dynamic fracture toughness of this tubes was qualified.

\section{References}

[1] P. Alart and A. Curnier. A generalized newton method for contact problems with friction. Journal de Mécanique Théorique et Appliquée, 7:67\{82, 1988.

[2] F. Dubois and M. Jean. Une plateforme de développement dédiée la modélisation des problèmes d'interaction. In $6^{\text {ème }}$ colloque national en calcul de structures - CSMA-AFM-LMS, volume 1, pages $111\{118$, Giens, 2003.

[3] M. Jean, V. Acary, and Y. Monerie. Non-smooth contact dynamics approach of cohesive materials. Phil. Trans. R. Soc. Lond., A359:2497\{2518, 2001.

[4] J.-C. Michel, P. Suquet, and F. Thébaud. Une modélisation du rôle des interfaces dans le comportement des composites matrice métallique. Revue Européenne des Eléments Finis, 3, 1994.

[5] Y. Monerie and V. Acary. Formulation dynamique d'un modèle de zone cohésive tridimensionnel couplant endommagement et frottement. Revue Européenne des Eléments Finis, 10:489\{503, 2001.

[6] J.-J. Moreau. Unilateral contact and dry friction in finite freedom dynamics. In J.-J. Moreau and P.D. Panagiotopoulos, editors, Non Smooth Mechanics and Applications, volume 302 of CISM Courses and Lectures, pages $1\{82$, Vienna, 1988. Springer.

[7] F. Perales, Y. Monerie, F. Dubois, and L. Stainier. Computational non-smooth fracture dynamics in nonlinear and heterogeneous materials. Application to fracture of hydrided Zircaloy. In Y. Zhou, S. Yu, and Y. Xu, editors, Structural Mechanics In Reactor Technology, volume 18, pages 274\{280, Beijing, China, 2005. Atomic Energy Press.

[8] B. Piar, L. Chailan, and D. Vola. Scientific software architectures designed to survive change. In Trend in Physical and Numerical of Multiphase Industrial Flows. Cargèse, 2003.

[9] M. Raous, L. Cangémi, and M. Cocu. A consistent model coupling adhesion, friction and unilateral contact. Computer Methods in Applied Mechanics and Engineering, 177(3\{4):383\{399, 1999.

[10] L. Stainier, F. Dubois, and R. Peyroux. MatLib, une bibliothèque portable de modèles constitutifs pour la mécanique non-linéaire des solides: concepts et implémentation. In $6{ }^{\text {ème }}$ Colloque National en Calcul des Structures - CSMA-AFM-LMS, Giens, 2003.

[11] P-G. Vincent, Y. Monerie, and S. Bourgeois. Homogénéisation du comportement élastoplastique des gainages de crayons combustibles. In Congrès Français de Mécanique, volume XVII, Troyes, 2005 . 